so much on trust. If Prof. Baer has discovered in the genital atrium a character which is dependablo-. a point which time alone will prove to everyone's satisfaction-it is a matter of great importance from the point of view of elucidating host/parasite relationships.

One minor point is worth noting: a fine trap is set for the English-speaking reader by the use here and there of vernacular names of the hosts. Thus, "Pingouin" equals razorbill, not penguin, and "Puffins" are shearwaters, not puffins in our sense. Miriam RothschiLD

\section{RADIO EMISSION FROM JUPITER}

$\mathrm{T}$ HE Carnegie Institution of Washington announced in April that radio emissions from Jupiter had been detected on a frequency of $22 \mathrm{Mc} / \mathrm{s}$. The receiving system consisted of a large cross aerial, of the type developed by Mills in Sydney for radio astronomy, which produces a narrow beam in a fixed direction. The Carnegie aerial occupies a 96-acre field near Seneca, Maryland, and although the beamwidth is not stated it may be deduced to be of the order of one degree from the fact that Jupiter passes through the aerial beam in six minutes. The radio emissions were reported to have the appearance of short random bursts of static resembling thunderstorm interference on a broadcast receiver and were observed about one day out of three during the time when Jupiter was in the beam of the aerial system. The location of the sky from which these bursts originated agreed with the position of Jupiter over a period of several months, and hence it can be presumed that any terrestrial origin of the bursts has thereby been excluded.

The study of radio waves from the sun is a wellknown and important part of radio astronomy. The signals are relatively intense; those from the quiet or undisturbed sun originate in the corona, which has an equivalent black-body temperature of the order of a million degrees at these low frequencies. Success has also been achieved in measuring the radio emission from the moon by Dicke and Beringer in 1946, and by Piddington and Minnett in 1949. In this case the emission measured, on a wave-length of $1.25 \mathrm{~cm}$., corresponds to the black-body radiation appropriate to a lunar surface temperature of $250^{\circ} \mathrm{K}$. 'The surface temperature of Jupiter measured at the top of the cloud layer is about $160^{\circ} \mathrm{K}$., and hence the signal bursts received by the Carnegie workers on $22 \mathrm{Mc} / \mathrm{s}$. must have quite a different origin from the solar or lunar emissions.

It has been suggested that the Jupiter signals are caused by disturbances in the planetary atmosphere similar to terrestrial thunderstorms, but on a much larger scale. It is possible to estimate the likelihood of this from the radiation field produced by a single lightning flash in the earth's atmosphere which, according to the measurements of E. T. Pierce, is $15 \mathrm{~V} . / \mathrm{m}$. at a distance of $20 \mathrm{~km}$. on a frequency of $1 \mathrm{Mc} / \mathrm{s}$. and band-width $1 \mathrm{Mc} . / \mathrm{s}$. At the distance of Jupiter the field-strength would be $5 \times 10^{-7} \mathrm{~V} . / \mathrm{m}$. and the power flux about $10^{-21}$ W. m..$^{-2}(\text { c. } / \mathrm{s} .)^{-1}$ at $1 \mathrm{Mc} . / \mathrm{s}$. Making reasonable assumptions about the frequency spectrum and remembering that in the terrestrial atmosphere the rate of occurrence is about a hundred flashes per second, it seems that the thunderstorm static from the earth at the distance of Jupiter would amount to about $5 \times 10^{-21}$ W. m.-2 (c./s.) ${ }^{-1}$, which would be readily detectable by contemporary techniques such as that used by the Carnegie workers. However, this signal would appear as a steady background, whereas the Jupiter signals occurred on only one day in three and were apparently in the form of bursts. It seems clear that the further development of this work may well provide new and valuable information about the conditions in the atmosphere of Jupiter.

\section{ABNORMAL PROTEIN ASSOCIATED WITH TOBACCO MOSAIC VIRUS \\ Structure of Polymerized Tobacco Plant Protein and Tobacco Mosaic Virus}

$\mathrm{W}$ HEN tobacco plants are infected with tobacco mosaic virus, an abnormal protein can be isolated from the tobacco leaves ${ }^{1}$. It has been demonstrated that this protein is non-infectious, is free of ribonucleic acid, and is immunologically related to the protein component of the virus. In addition, this protein has the peculiar property of polymerizing into rod-like structures when brought close to its isoelectric point at $p \mathrm{H} 3 \cdot 8$. In the electron microscope, these rods appear to be similar to tobacco mosaic virus rods, except that their length is more variable than that of freshly harvested tobacco mosaic virus.

There has been some debate concerning the exact nature of these nucleic acid-free rods, which appear so similar to tobacco mosaic virus, ${ }^{2,3}$. A recent amino-acid analysis has shown that the composition of the abnormal protein is virtually identical to that of the protein component of the virus ${ }^{4}$. Here we wish to present $\mathrm{X}$-ray diffraction evidence which demonstrates that the internal structure of the nucleic acid-free particles is similar to that of tho virus.

Samples of the abnormal protein from tobaceo plants were prepared by methods which have been described previously ${ }^{3}$. Freedom from contamination with tobacco mosaic virus was assured by the following tests : (a) When the abnormal protein is prepared in unpolymerized form at $p \mathrm{H} 7$, there is no highmolecular weight component observable in the ultracentrifuge, and no evidence of a rapidly migrating component in electrophoresis. (b) The ultra-violet absorption spectrum is that of a protein free of nucleic acid, with the ratio of optical densities at $280 \mathrm{~m} \mu$ and $260 \mathrm{~m} \mu$ of $1 \cdot 6-1 \cdot 7$; for tobacco mosaic virus this ratio is $0 \cdot 83$. (c) Electron micrographs of unpolymerized abnormal protein show no tobacco mosaic virus-like rods. (d) The material is not infectious. In summary, the contamination of abnormal protein by tobacco mosaic virus, if any, should be considerably less than 1 per cent.

The abnormal protein was gradually brought to its isoelectric point, and typical rod-like forms were observed in the electron microscope. Oriented airdried films of this material and of tobacco mosaic virus grown on the same tobacco plants were prepared by the microscope slide technique of Bernal 